\title{
Gebruik van persoonsnamen in de Nederlandse vaktaal van de geneeskunde
}

\section{Use of Personal Names in Dutch Medical Language for Special Purposes}

\author{
Ewa Majewska
}

\begin{abstract}
Personal names play an important role in the medical language. Medical terms often consist of eponyms. A lot of expressions like ziekte van Basedow, ziekte van Hashimoto, syndroom van Down, Achillespees or doppleronderzoek are permanent ingredients of medical vocabulary. The eponyms can substitute long and complicated descriptions of medical terms. For specialists they have a clear meaning but on the other hand eponyms can cause confusion if there are used by people who have no medical education. An eponym can have two different meanings and the same illness can be described by two different persons what independently happens. What is the structure of an eponym? There are a lot of possibilities of naming an illeness, a syndrome or a part of body with an eponym. In many cases diseases, instruments or another medical units have been named after their discoverers or describers. This paper presents eponyms who have been collected from the Dutch medical press. They have been analysed in respect of their morphology and semantics, and have been splitted into groups.
\end{abstract}

\section{Keywords}

language for special purposes, medical language, eponyms, medical press, personal names 
Elke taal van de wetenschap heeft behoefte aan vaktermen die het belangrijkste bestanddeel van deze vaktaal zijn. Fluck beweert dat er ongeveer 300 vak- en beroepstalen bestaan die in verband met bepaalde vak- en beroepsdomeinen staan (FLUCK 1976: 16).

De medische vaktaal neemt een bijzondere plaats in onder de vaktalen, want niemand kan ervan afstand doen. Iedereen wordt ermee vroeger of later geconfronteerd. Kenmerkend voor deze taalvariant is zijn bijzonder uitgebreide terminologie. Deze rijke vakwoordenschat ontwikkelde zich gedurende meer dan 2000 jaar. De beginselen van de medische vaktaal liggen in de Griekse taal. De grondslag voor de Europese geneeskunde werd in de Griekse artsenscholen gelegd (LIPPERT 1979: 88; VERMIJ 2007: 20-21). Ondanks de toenemende invloed van het Latijn bleef het Grieks in de middeleeuwen toch als taal van de wetenschap bestaan (LIPPERT 1979: idem). Deze taal is dan ook niet helemaal uit de geneeskunde verdwenen, de Griekse vakbegrippen werden door de Romeinen overgenomen, aangevuld en aan het Latijn aangepast (GROSCHE 2002: 3). Talrijke nog steeds gebruikelijke benamingen van ziektes gaan op de antike scholen terug, bijv. asthma, eclampsie of gangreen (KÜHTZ 2007: 38). Na de val van het Romeinse Rijk werd de Griekse geneeskunde door Arabische artsen bewaard en verder ontwikkeld en er werden nieuwe woorden in de medische vaktaal ingevoerd. Van de Arabieren zijn o.a. termen afkomstig zoals alcohol, kamfer, bismut (WILLMANNS/SCHMITT 2002: 17). Volgens POREP en STEUDEL (1983:14) hebben naast klassieke talen ook het Frans en het Italiaans en talen uit Zuidamerika enigszins tot het vormen van de medische vaktaal bijgedragen. Tegenwoordig speelt het Engels als taal van de wetenschap een steeds belangrijkere rol in de woordvorming van de medische vakbegrippen. Engelse woorden worden vaak onveranderd overgenomen, bv. string sign (vgl. KÜHTZ 2007: 40). De tegenwoordige medische vakwoordenschat omvat 500.000 eenheden, waarvan 20.000 als benamingen van organische functies, 60.000 van ziektes, onderzoeks- en operatiemethodes gebruikt worden (POREP/STEUDEL 1974, V,9/ vgl. AHLHEIM 1992, SCHIPPERGES 1988). De totale omvang van de medische vakwoordenschat bedraagt volgens KEMPCKE (1989: 843) ca. twee miljoen woorden.

Persoonsnamen maken deel uit van veel medische termen. Meestal zijn dat achternamen van ontdekkers of eerstbeschrijvers van lichaamsdelen, ziektes, syndromen, instrumenten, bacteriën, parasieten, effecten, eenheden, formules, wetten, handkunstgrepen, hypothesen, aanwijzingen, constanten, fenomenen, proeven, reacties, regels, symptomen, theorieën, tekens, cellen, procedés, tests, theoriën, pathologische verschijnselen etc. Deze termen worden in de medische vaktaal ,eponiemen' genoemd (vgl. LEIBER/OLBERT 1968).

Medische eponiemen spelen een beduidende rol in de medische vakwoordenschat (WINKELMANN 2009: IX). De term ,eponiem' is afgeleid van de Griekse woorden epi ,bij' en onoma ,naam'. De eponiem is dus de naam van een persoon, naar wie de zaak vernoemd wordt. Voorbeelden van eponiemen zijn ziekte van Basedow, achillespees, doppleronderzoek, hashimoto-thyreoiditis, syndroom van Down, brodieabces, arterie van Adamkiewicz, adams-operatie. 
Persoonsnamen staan in de Nederlandse geneeskundige term als leden van een naamwoordelijke samenstelling, bv. alzheimerdementie, soms met een streepje ertussen, bv. eisenmenger-syndroom, of ze horen bij een losse aaneenschakeling van woorden, bv. bacillus Morgan, zijn afleidingen, bv. parkinsonisme of bijvoegelijke bepalingen, bv. $b a-$ kerse cyste, of naamwoordelijke bestanddelen van een voorzetselgroep, bv. formule van Laplace. Een bijzondere vorm van eponiemen zijn polyniemen, die uit meer dan één persoonsnaam bestaan, bv. parker-weber-syndroom. Gelijke structuren komen ook in de Duitse taal van de geneeskunde voor (vgl. MAJEWSKA 2016).

Hoe worden de eponiemen in het Nederland gespeld? Volgens de officiele spellingsregels worden de persoonsnamen in eponiemen mit geen beginhoofdletter geschreven. Het streepje vervaalt behalve als de persoonsnamen gekoppeld zijn, bv. budd-chiarisyndroom en bij zulke eponiemen die uit meerledige namen bestaan, bv. gilles-de-la-tourettesyndroom. De spellingsregels laten ook keuzenmogelijkheden omwille van de leesbaarheid toe en het is mogelijk een of meer streepjes te handhaven (VAN EVERDINGEN et al. 2006: 371).

De eerste medische eponiemen zijn afkomstig uit de anatomie. Volgens de Vlaamse arts, Andreas Vesalius, hebben vanaf de 16de eeuw generaties van anatomen de organen nauwgezet bestudeerd en hun ontdekkingen met hun naam voorzien. Zo was het met de Italiaanse anatoom Bartolomeo Eustachi (1520-1574) die zijn eerste ontdekkking van de ,oortrompet' als tuba Eustachii noemde (WILLMANNS/ SCHMITT 2002: 19). In het midden van de 19de eeuw begon men in de neurologie ziektebeelden met persoonsnamen te benoemen. Vanaf het begin van de 20ste eeuw wordt dit procédé in bijna alle klinische vakken gebruikt (WIESE 1984: 43). Door het vernoemen met auteursnamen worden verdiensten van een arts, een ontdekker of eerstbeschrijver van een ziekte, syndroom, instrument vereerd. De term ziekte van Koch is gevormd naar Robert Koch, de ontdekker van de tuberculosebacteriën. Medische eponiemen behoren niet meer tot officiele anatomische nomenclatuur hoewel sommige ervan wel op lichaamsdelen betrekking hebben, bv. achillespees, adamsappel (JOCHEMS 2010: 92).

Voor vakmensen hebben de uit een persoonsnaam en een appellatief bestaande vaktermen een duidelijke betekenis, maar de niet ingewijden kunnen soms daardoor in verwarring raken, vooral als men de persoonsnaam met geen concrete ziekte of syndroom associeert. De persoonsnaam als bestanddeel van het vakbegrip ziekte van Hirschsprung is dus niet voor iedereen begrijpelijk. Het eerste deel van de eponiem verbergt een vakkundige informatie die pas dan aan het licht komt als men iets meer over het werk van Harald Hirschsprung, zijn naamgever, te weten komt. Voor de leken die deze naam voor de eerste keer horen, is dit begrip helemaal onduidelijk. Volgens JOCHEMS (2010: 91) hebben de persoonsnamen in de geneeskundige termen toch een groot voordeel, omdat men door hun gebruik lange en soms ingewikkelde omschrijvingen kan vermijden.

Medische eponiemen kunnen ook om andere reden tot verwarring aanleiding geven. Een bepaald eponiem kan soms twee betekenissen hebben, bv. ziekte van Paget, de ziekte van Von Recklinghausen en het lichaampje van Malpighi. De ziekte van Paget kan op 
een chronische botontsteking (ostitis deformans) of op een oppervlakkig tepelcarcinoom duiden. Als men de term ziekte van Von Recklinghausen onder de loep neemt dan kan deze term van goedaardige huidgezwellen (neurofibromen) getuigen of botvervorming door een hyperfunctie van de bijschildklieren betekenen. Het lichaampje van Malpighi wijst op een nierlichaampje in de nieren maar tegelijkertijd kan deze naam ook op een lymfefollikel in de milt betrekking hebben (JOCHEMS 2010: 91).

Persoonsnaamen die een vakbegrip vormen komen met verschillende appellativen voor. Er moet onderscheiden worden tussen ziekte en syndroom, complex van verschijnselen' die vaker in eenzelfde combinatie voorkomen en die daarom als hetzelfde begrip worden opgevat', bv. parkinson-ziekte en parkinsonisme. Verdere problemen leveren de auteurs / eerstbeschrijvers van een verschijnsel zelf want dezelfde ziekte of hetzelfde syndroom zijn vaak door twee of meer verschillende personen onderzocht en beschreven. Soms is dat helemaal onafhankelijk van elkaar gebeurd, b.v. de ziekte van Basedow is in Engeland bekend als Grave's disease, in Polen gebruikt men de term choroba Graves'a-Basedowa.

De meeste eponiemen hebben betrekking op namen van ziektes. De persoonsnaam maakt in dit geval deel uit van een voorzetselgroep en gaat gepaard met het woord ,ziekte', bv. ziekte van Addison, ziekte van Alibert, ziekte van Albright, ziekte van Alzheimer, ziekte van Albers-Schönberg, ziekte van Behr, ziekte van Blocq, ziekte van Buerger, ziekte van Cowden, ziekte van De Almeida, ziekte van Dressler, ziekte van Fabry, ziekte van Heine-Medin, ziekte van Hodgkin, ziekte van Kahler, ziekte van Leber, ziekte van Münchmeyer, ziekte van Pick, ziekte van Pinkus, ziekte van Scheuermann, ziekte van Sternberg, ziekte van Tornwaldt, etc.

Bij een aantal ziektes komt het word ziekteniet te voorschijn. De eponiem is het eerste lid van de samenstelling, bv. alzheimerdementie, alzheimerfibrilleren, kienböck-atrofie, pick-hersenatrofie, sudeck-botatrofie, bárány-dofheid, eichhorstneuritis, flexnerdysenterie, fanconianemie.

In de volgende voorbeelden komt in plaats van het word ziekte een ander appellatief voor en de persoonsnaam staat helemaal achter in de woordgroep, bv. angina van Plant-Vincent, atrofie van Duchenne.

Behalve ziektes worden ook syndromen met persoonsnamen gevormd. De persoonsnaam maakt deel uit van een samenstelling of bestaat uit twee woorden die met een streep verbonden zijn. Vaak zijn deze twee spellingsvormen gebruikelijk:

aarkkogsyndroom/aarskog-syndroom, adams-stokes-syndroom, alagillesyndroom/alagille-syndroom, aldrich-wiskottsyndroom, albrightsyndroom /albright-syndroom, arnold-chiarisyndroom /arnold-chiari-syndroom, bantisyndroom/banti-syndroom, barlowsyndroom /barlow-syndroom, syndroom van Caplan, fröhlichsyndroom, fanconi-syndroom, edwards-syndroom, korsakovsyndroom, syndroom van Horton-Magath-Brown,

De volgende groep omvat voorbeelden van benamingen van symptomen die van een persoonsnaam voorzien zijn, bv. babinskisymptoom / babinski-symptoom, bergersymptoom / berger-symptoom, codmansymptoom /codman-symptoom, cullensymptoom /cullen-symptom, duchennesymptoom, froment-symptoom, heryngsymptoom/ heryng-symptoom, etc.

Persoonsnamen staan ook in de namen van symptomen die zonder het word symptoom gebruikt worden, bv. austin-flint-hartgeruis, duroziegeruis. 
Behalve ziektes, syndromen en symptomen hebben ook andere in de geneeskunde voorkomende appellativen een persoonsnaam erbij. Een aantal eponiemen komt met het word formule voor, bv. friedwaldformule, formule van Laplace, formule van Read, dubois-formule. Ook namen van fracturen krijgen vaak een persoonsnaam erbij, bv.fractuur van De Quervain, smithfractuur, le-fort-I-fractuur,

Er worden ook bacteriën, virussen en parasieten naar hun ontdekkers of eerstbeschrijvers vernoemd. Ze komen ook als afleidingen voor, bv. babesia (Victor Babes), bartonella (John Barton), bedsonia (Samuel Bedson), of zij gaan gepaard met het word bacil of bacillus in een voorzetselgroep, bv. bacil van Koch, bacil van Morax-Axenfeld, bacil van Shiga-Kruse, bacil van Welch, bacil van Yersin/ yersinbacil, maar ook als losse aaneenschakelingen zonder het voorzetsel van: bacillus Calmette-Guérin, bacillus Morgan, Bacillus Pfeiffer. Ze kunnen ook als samenstellingen voorkomen, bv. döderleinbacil, ducreybacil, epstein-barrvirus, flexnerbacil, strongbacil.

Persoonsnamen zijn bestanddelen van pathologische verschijnselen, gezwellen, nieuvormingen, bv. acrosarcoma Kaposi, bednartumor, codmantumor, conntumor, bezoldabces, brodieabces, desaultabces, douglasabces, bakercyste, ewingsarcoom, douglasmetastase.

Een groot deel van anatomische lichaamsdelen houdt persoonsnamen in, bv. arterie van Adamkiewicz, albiniknobbeltjes, alzheimercellen, anitsjkow-cellen, kanaal van Arantius, aschoffcellen, baan van Burdach, baan van Flechsig, baan van Goll, band van Hesselbach, band van Reil, band van Weber, fontanabanden, fontanakanaal, giacominiband, henleband, miles-lord-pectenbanden, barr-lichaampje, bellinibuisjes, betzcellen, luschkabeurs, bilrothbalkjes, cortimembraan, davidoff-cellen, halve manen van Gianuzzi, giraldésorgaan, gierkelichaampjes, bundel van Gierke, kanaal van Petit, henlelaag.

Ook operaties en chirurgische ingrepen worden door een persoonsnaam vergezeld: antyllusoperatie, adams-operatie, aldridgeoperatie, amputatie volgens Bier, amputatie vol gens Bunge, amputatie volgens Gritti, amputatie volgens Carden, amputatie volgens Krukenberg, amputatie volgens Langenbeck, amputatie volgens Lisfranc, amputatie volgens Madden, chopartamputatie, grittiamputatie, pateyamputatie, barraquer-lensextractie, dührssenoperatie.

Eponiemen maken ook deel uit van reacties, bv. reactie van Adamkiewicz, cholerareactie van Beijerinck, benedict-suikerreactie, bial-reactie, van technieken, bv. alexander-techniek, alexander-behandeling, handgreep van Barlow, cohn-proef, loopproef volgens Babinski-Weill; van diverse methodes, bv. confrontatiemethode volgens Donders, dopplermetrie, gerotamethode, van diëten, bv. giordano-giovannettidieet, van tests, bv. binet-simon-test, combs-test, van voedingsboden voor bacteriën, bv. platen van Eijkman; van stoffen, bv. combs-serum; van instrumenten, bv. baginskyhaakje, barcroftapparaat, beckman-ringmes, bénique-sonde, bermanlocalisator, collin-tang, cooper-schaar, crutchfield-klem, cunningham-klem, spirale van Curschman, bus van Dührssen, edelmansfluit, cooper-schaar, crisissen, bv. addisoncrisis; of van wetten, bv. wet van Bell; effecten, bv. dopplereffect.

Behalve naar eerstbeschrijvers of ontdekkers wordt er ook naar patiënten vernoemd, bij wie de concrete ziekte of syndroom voor het eerst waargenomen is, bv. hartnupziekte, naar de eerste patiënt Edward Hartnup; helacellen, naar de eerste patiente Henrietta Lacks. Vanuit ons perspectief is verbazend en moeilijk om erachter te komen waarom uiteraard de namen van de patiënten belangrijker waren dan de 
namen van de onderzoekers en artsen. In elk geval hebben de eerstbeschrijvers van bovengenoemde ziektes deze namen toch geaccepteerd.

Persoonsnamen als delen van medische termen worden behalve in het ziekenhuis of in de polikliniek in mondelinge communicatie tussen de artsen en het medische personeel ook in de Nederlandstalige medische vakpers gebruikt.

De voor het onderzoek gebruikte eponiemen zijn afkomstig van het medische tijdschrift Nederlands Tijdschrift voor Geneeskunde 2011 dat voor artsen bestemd is. Ze werden naar hun structuur en de wijze van vernoeming onderzocht.

In het onderzoeksmateriaal zijn er samenstellingen verzameld die uit een eponiem als het eerste lid opgebouwd zijn, bv. achillespees, achillespeesruptuur, alzheimerdementie, bechterewpatiënt, behçetpatiënten, bonnetsyndroom, cogansyndroom, doppleronderzoek, dotterbehandeling, friedreichataxie, heckerlingscore, hodgkinlymfoom, kaposisarcoom, kawasakivasculitis, langerhanscellen, lynchsyndroom, massontumor, mazabraudsyndroom.

Er komen ook samenstellingen met een streep tussen beide delen voor, bv. eisenmenger-syndroom, cornelia-de-lange-syndroom, cowden-syndroom, kaposi-sarcoom, kirschner-draden, küttner-tumor, lyell-syndroom, mardkov-model, meckel-divertikel, mees-symptoom, mirizzi-syndroom, proteus-syndroom, wharton-gelei.

In het onderzoeksmateriaal treden er ook afgekorte vormen van eponiemen op die alleen met de persoonsnaam zonder het appellatief gebruikt worden: bv. alzheimer, hashimoto.

De taalcorpus omvat tevens polyniemen die uit meer dan één persoonsnaam bestaan, bv. baden-walker-systeem, björk-siley-klep, bloom-richardson-graad, epstein-barrvirus, henoch-schönleinpurpura, howell-jollylichaampjes, rumack-matthew-nomogram, guillain-barrésyndroom, parkes-weber-syndroom, stevens-johnson-syndroom, churg-strausssyndroom, wernicke-korsakov-syndroom, wolf-parkinson-white-syndoom.

De eponiem heeft ook de functie van de bijvoegelijke bepaling bij een appellatief, bv. bakerse cyste.

Sommige eponiemen komen in een reeks van woorden voor die een begrip vormen, bv. cavum douglasi, morbus masculosus werlhofi.

De persoonsnamen komen in de medische vaktermen niet alleen in samenstellingen, in losse aaneenschakelingen of als bijvoegelijke bepalingen voor, maar ze worden ook afgeleid. Zo'n voorbeeld van een afleiding is het syndroom parkinsonisme, wiens naam uit de eigennaam Parkinson ontstaan is.

Taalrijk zijn de eponiem die bestanddelen van een voorzetselgroep met het voorzetsel van zijn, bv. de boog van Treitz, eed van Hippocrates, fenomeen van Raynaud, gang van Stensen, nodulus van Herberden, nodulus van Bouchard, pseudoteken van Nokolsky, punt van McBurney, ligament van Treitz, lijnen van Muehrke, syndroom van Cowden, syndroom van Cushing, syndroom van Gardner, syndroom van Gilles, syndroom van Horner, syndroom van Jacobsen, syndroom van Lowe, syndroom van Lynch, syndroom van Lyell, syndroom van Mazabraud, teken van Brudzinski, teken van Kernig, teken van Kehrer, teken van Murphy, teken van Nikolsky, teken van Rovsing, ziekte van Alzheimer, ziekte van Bechterew, ziekte van Behçet, ziekte van Buerger, ziekte van Chagas, ziekte van Crohn, ziekte van Dent, ziekte van Duchenne, ziekte van Freiberg, ziekte van Gaucher, ziekte van Gaucher, ziekte van Hirschsprung, 
ziekte van Hodgkin, ziekte van Huntington, ziekte van Kawasaki, ziekte van Lyme, ziekte van McArdle, ziekte van Méniere, ziekte van Mondor, ziekte van Ollier, ziekte van Parkinson, ziekte van Pompe, ziekte van Sjörgen, ziekte van Still, ziekte van Wegener, ziekte van Willebrand, ziekte van Wilson.

Enkele persoonsnamen treden als polyniemen in de voorzetselgroepen op, bv. syndroom van Bannnayan-Zonana, syndroom van McCune-Albright, syndroom van Noonan -Jacobsen, syndroom van Peutz-Jeghers, syndroom van Wiskott-Aldrich, syndroom van Stevens-Johnson, ziekte van Ehlers-Danlos, ziekte van Filatow-Dukes, ziekte van Rosai-Dorfman.

De eponiemen laten zich semantisch indelen. De meeste eponiemen bevatten namen van de ontdekkers of eerstbeschrijvers die betrekking op anatomische structuren hebben, bv. langerhanscellen (Paul Langerhans), de boog van Treitz (Wenzel Treitz), cavum Douglasi (James Douglas), gang van Stensen (Niels Stensen), howell-jollylichaampjes (William Henry Howell), bakerse cyste (William Morrant Baker).

Er werden syndromen, symptomen of anatomische structuren naar een fictieve figuur vernoemd, bv. achillespees, achillespeesruptur (mythologische Figuur, Oudgriekse held), proteus-syndroom (Griekse zeegod), pickwicksyndroom (titelfiguur van het boek van Charles Dickens).

De verzamelde vakbegrippen bevatten namen van bacteriën, virussen, parasieten, bv. epstein-barrvirus (M.A. Epstein/M.L.Barr).

Als eponiemen komen ook namen van de ontdekkers of eerstbeschrijvers van pathologische veranderingen, processen, ziektesymptomen voor, bv. hodgkinlymfoom (Thomas Hodgkin), kaposisarcoom (Moritz Kohn Kaposi), kawasakivasculitis (Tomisaku Kawasaki), wilmstumor (Max Wilms), mees-symptoom (R.A. Mees), friedreichataxie (Nicolaus Friedreich), alzheimerdementie (Alois Alzheimer).

Er werden namen van ziektes een syndromen gevonden die persoonsnamen bevatten, bv. alzheimer (Alois Alzheimer), hashimoto (Hakaru Hashimoto), sjörgensyndroom (Henrik Sjörgen), bechterewpatiënt (W.M. Bechterew), cogansyndroom (David Glendening Cogan), lynchsyndroom (Henry T. Lynch), eisenmenger-syndroom (Victor Eisenmenger), mirizzi-syndroom (Pablo L. Mirizzi), syndroom van Cushing (Harvey Cushing), syndroom van Jacobson (Ludwig Levin Jacobson), syndroom van Noonan (Jaqueline A. Noonan), ziekte van Alzheimer (Alois Alzheimer), ziekte van Bechterew (W.M. Bechterew), ziekte van Behçet (Hulushi Behçet), ziekte van Buerger (Leo Buerger), ziekte van Freiberg (Albert Henry Freiberg), ziekte van Hirschsprung (Harald Hirschsprung), ziekte van Hodgkin (Thomas Hodgkin), ziekte van Kawasaki (Tomisaku Kawasaki), ziekte van Méniere (Prosper Méniere), ziekte van Mondor (Henri Mondor), ziekte van Parkinson (James Parkinson), ziekte van Pompe (Joannes Cassianus Pompe), ziekte van Sjörgen (Henrik Sjörgen), ziekte van Willebrand (Erik A. von Willebrand), guillain-barrésyndroom (G. Guillain, J.A.Barré), stevens-johnson syndroom (Albert Stevens, Frank Johnson), churg-strausssyndroom (Jacob Churg, Lotte Strauss), syndroom van Wiskott-Aldrich, (Alfred Wiskott, Robert Aldrich).

Namen van symptomen worden ook met een eponiem gebruikt, bv. teken van Kernig (Vladimir Kernig), teken van Brudzinski (Josef von Brudzinski).

De meeste medische eponiemen stammen van de ontdekkers of eerstbeschrijvers van een ziekte of een ander medisch verschijnsel. Er worden ook eponiemen 
van tweede beschrijvers gevormd. In het volgende voorbeeld is een pathologisch verschijnsel naar de tweede beschrijver vernoemd: massontumor (Pierre Masson). Een uitzondering is zeker de vernoeming naar de eerste patient, bv. syndroom van Cowden/ cowden-syndroom (Rachel Cowden).

Eponiemen zijn tevens in de namen van medische verschijnselen een fizjologische processen terug te vinden die hun naam aan hun eerstbeschrijver te danken hebben, bv. fenomeen van Raynaud (Maurice Raynaud). Op gelijke wijze zijn een aantal namen van medische instrumenten onstaan. De ontwerpers ervan hebben ook aan de naam van het instrument deelgenomen, bv. kirschner-draden (Martin Kirschner), björk-shileyklep (Viking Björk, Don Shiley). Hetzelfde geldt voor de auteurs van geneeskundige methodes of procedures, bv. doppleronderzoek (Ch. Doppler), röntgenonderzoek (Wilhelm Konrad Röntgen).

Het onderzoek omvat Nederlandse eponiemen die uit de Nederlandstagige medische tijdschrift afkomstig zijn. Deze eponiemen zijn producten van diverse woordvormingsprocedés. Van de onderzochte subtantieven zijn 30\% samenstellingen, 1,5\% afgekorte vormen, $10 \%$ polyniemen, $0,8 \%$ eponimische attributen in een woordgroep, $1,5 \%$ losse aaneenschakelingen, $49 \%$ eponiemen in voorzetselgroepen (daaronder $7 \%$ polyniemen). $95 \%$ van de eponiemen zijn naar de eerstbeschrijvers vernoemd, $5 \%$ naar de eerste patienten, de tweede beschrijver of fiktieve figuren. De meeste gevonden eponiemen hebben betrekking op ziektes en syndromen (45\%), symptomen $(6 \%)$, anatomische structuren $(7 \%)$, de overige eponiemen zijn benamingen van instrumenten, virussen, etappen van een ziekte.

Op grond van de bovenstaande zal het duidelijk zijn dat de auteurs van de Nederlandstalige medische vakpers in hun artikelen wel medische eponiemen gebruiken. Hun aantal is in de onderzochte tijdschriften niet bijzonder hoog maar naar het blijkt laten zich de eponiemen uit de vaktaal van de geneeskunde niet verwijderen. Ze kunnen in verschillende morfologische structuren voorkomen en meestal zijn ze van de namen van ontdekkers of eerstbeschrijvers afkomstig. De eponiemen zijn een vast bestanddeel van de medische vakbegrippen, ook in de medische pers, en het zal waarschijnlijk nog lang zo blijven. Een van de redenen voor het gebruik van eponiemen in de medische vaktaal kan zijn dat ze vaak makkelijker te onthouden en te gebruiken zijn dan de gecomplieceerde Latijs-Griekse termen die vaak uit meer dan twee leden bestaan.

\section{Bibliografie}

AHLHEIM, Karl-Heinz (1992): Duden. Das Wörterbuch medizinischer Fachausdrücke. Mannheim, Leipzig, Wien, Zürich.

GROSCHE, Günther (2002): Übungsheft zur Einführung in die medizinische Fachsprache, Reinbek.

FLUCK, Hans-Rüdiger (1976): Fachsprachen, München.

JOCHEMS, A.A.F. (2010): Medische termen in word en geschrift, Houten. 
KEMPCKE, Günther (1989): Probleme der Beschreibung fachsprachlicher Lexik im allgemeinen einsprachigen Wörterbuch. In: Hausmann, F. J./ Reichmann, O./ Wiegand, H. E./ Zgusta, L. (eds): Wörterbücher Dictionaries Dictionnaires. Ein Handbuch zur Lexikographie, Bd.1, Berlin, New York, p. 842-849.

KÜHTZ, Stefan (2007): Phraseologie und Formulierungsmuster in medizinischen Texten, Tübingen.

LEIBER, Bernfried, OLBERT, Theodor (1968): Die klinischen Eponyme. Medizinische Eigennamenbegriffe in Klinik und Praxis.

LIPPERT, Herbert (1979): Sprachliche Mittel in der Kommunikation im Bereich der Medizin. In: Mentrup, W. (ed.): Fachsprachen und Gemeinsprache. Jahrbuch 1978 des Instituts für deutsche Sprache, Düsseldorf.

MAJEWSKA, Ewa (2016): Eponyme in der deutschsprachigen medizinischen Fachpresse. In: Hough, Carole/ Izdebska, Daria (eds.): Names and Their Environment. Proceedings of the $25^{\text {th }}$ International Congress of Onomastic Sciences, Glasgow, 25-29 August 2014, Volume 4: Theory and Methodology, Glasgow, p. 94-104, http://www.icos2014.com/wp-content/uploads / icos2014_vol_4.pdf.

POREP, Rüdiger, STEUDEL, Wolf-Ingo (1974): Medizinische Terminologie. Ein programmierter Kurs zur Einführung in die medizinische Fachsprache, Stuttgart.

SCHIPPERGES, Heinrich (1988): Die Sprache der Medizin. Medizinische Terminologie als Einführung in das ärztliche Denken und Handeln. Heidelberg.

VAN EVERDINGEN, J.J.E. et al. (ed.) (2006): Pinkhof Geneeskundig Woordenboek, Houten.

VERMIJ, Rienk (2007): Kleine geschiedenis van de wetenschap, Amsterdam.

WIESE, Ingrid (1984): Fachsprache der Medizin. Eine linguistische Analyse, Leipzig (Linguistische Studien).

WILMANNS, Juliane C., SCHMITT, Günther (2002): Die Medizin und ihre Sprache, Landsberg/ Lech.

WINKELMANN, Andreas (2009): Von Achilles bis Zuckerkandl. Eigennamen in der medizinischen Fachsprache, Bern.

Dr. Ewa Majewska / e.m.majewska@uw.edu.pl

Uniwersytet Warszawski, Instytut Germanistyki

Ul. Dobra 55, 00-312 Warszawa, Poland 
